Article

\title{
Applications and Limits of Time-to-Energy Mapping of Protein Crystal Diffraction Using Energy-Chirped Polychromatic XFEL Pulses
}

\author{
Alisia Fadini ${ }^{1}$, Sven Reiche ${ }^{2}$, Karol Nass ${ }^{2}$ and Jasper J. van Thor ${ }^{1, *(1)}$ \\ 1 Molecular Biophysics, Imperial College London, London SW7 2AZ, UK; alisia.fadini15@imperial.ac.uk \\ 2 Paul Scherrer Institut, CH-5232 Villigen PSI, Switzerland; sven.reiche@psi.ch (S.R.); karol.nass@psi.ch (K.N.) \\ * Correspondence: j.vanthor@imperial.ac.uk
}

Received: 5 March 2020; Accepted: 1 April 2020; Published: 9 April 2020

\begin{abstract}
A broadband energy-chirped hard X-ray pulse has been demonstrated at the SwissFEL (free electron laser) with up to $4 \%$ bandwidth. We consider the characteristic parameters for analyzing the time dependence of stationary protein diffraction with energy-chirped pulses. Depending on crystal mosaic spread, convergence, and recordable resolution, individual reflections are expected to spend at least $\approx 50$ attoseconds and up to $\approx 8$ femtoseconds in reflecting condition. Using parameters for a chirped XFEL pulse obtained from simulations of $4 \%$ bandwidth conditions, ray-tracing simulations have been carried out to demonstrate the temporal streaking across individual reflections and resolution ranges for protein crystal diffraction. Simulations performed at a higher chirp $(10 \%)$ emphasize the importance of chirp magnitude that would allow increased observation statistics for the temporal separation of individual reflections for merging and structure determination. Finally, we consider the fundamental limitation for obtaining time-dependent observations using chirped pulse diffraction. We consider the maximum theoretical time resolution achievable to be on the order of 50-200 as from the instantaneous bandwidth of the chirped SASE pulse. We then assess the ability to propagate ultrafast optical pulses for pump-probe cross-correlation under characteristic conditions of material dispersion; in this regard, the limiting factors for time resolution scale with crystal thickness. Crystals that are below a few microns in size will be necessary for subfemtosecond time resolution.
\end{abstract}

Keywords: XFEL; Laue crystallography; ultrafast dynamics

\section{Introduction}

With serial femtosecond crystallography (SFX) at X-ray Free Electron Lasers (XFELs), pump-probe data of protein structural dynamics with femtosecond time resolution can be obtained. In an SFX experiment, protein structures are determined by merging thousands of stationary diffraction patterns from single femtosecond XFEL pulse exposures. Several time-resolved experiments have been reported with SFX [1-7] and have allowed, for example, measurement of difference electron density maps identifying conformational changes as early as approximately $140 \mathrm{fs}$ for the photoactive yellow protein (PYP) [1], 49-406 fs in bacteriorhodopsin [7], and $1 \mathrm{ps}$ in the rsEGFP2 fluorescent protein [4]. Pump-probe SFX can therefore provide a description of the mechanistic connection between structural dynamics at different timescales (from ultrafast to millisecond) in photoactivated systems.

The bandwidth for an XFEL pulse, when operated in self-amplified spontaneous emission (SASE) mode, is on the order of $\triangle \mathrm{E} / \mathrm{E} \approx 0.2 \%$ [8-10]. The SASE process relies on the emission of spontaneous radiation by electrons in the first section of an undulator that is then itself the X-ray seed for the FEL [11-14]. As spontaneous radiation emission from the electrons is stochastic, the SASE 
radiation arises from microbunching with spectral and energy fluctuations [13-16]. With a typical SASE bandwidth in the range of $0.2 \%$, the majority of the reflections in protein SFX are partials [17], meaning that the full intensities of Bragg reflections are not recorded from a single crystal. A Monte Carlo integration technique is commonly used in order to determine the average values of structure factor amplitudes [18,19]. Based on the postrefinement procedure for oscillation data [20,21], methods for partiality assignment have been developed [22-26], in addition to integration, that can significantly improve merging statistics of SFX data [22,27]. These define partialities by modeling the overlap between the reciprocal space lattice point volume and the set of Ewald spheres that constitutes the beam [24]. Initial estimates of the full intensities are obtained from partiality values and these estimates are then improved in an iterative manner through agreement across the entire dataset [22]. An alternative approach would be to use polychromatic X-ray beams that fully integrate many reflections, as in the Laue technique. In Laue crystallography, the bandwidth is large enough that many reflections sit entirely within the Ewald sphere volume in reciprocal space and are therefore fully recorded. A serial polychromatic crystallography approach has been demonstrated with "pink"-beam undulator radiation and a bandwidth of $2.5 \%$ at synchrotrons $[28,29]$. At XFELs, the use of increased bandwidth for serial crystallography could improve the partiality determination and postrefinement results, though structure factor amplitude noise from the spectral fluctuation intrinsic to SASE operation remains present. A source of increased uncertainty is also the reduced flux under conditions of reflection, as the pulse energy is essentially divided over a larger frequency range.

The new compact XFEL source at the Paul Scherrer Institute, SwissFEL, is able to operate in a broad-bandpass mode: simulated ultrafast hard X-ray SASE pulses have a bandwidth as large as $\Delta E / E \approx 4 \%[30,31]$. Such pulses at SwissFEL display an energy chirp, meaning that the central frequency varies with time. The $\mathrm{X}$-ray energy chirp is obtained through an energy chirp of the electron beam: in contrast to standard operation, the energy chirp of the electron bunch is purposefully increased through overcompression in the last bunch compressor [30]. This scheme can maximize the chirp of the electron beam, and thus that of the X-rays. Currently, $4 \%$ is the maximum achievable chirp expected for hard $\mathrm{X}$-rays at SwissFEL, though the possibility exists to increase the chirp with a dechirper device [32,33].

The possibility of exploiting an energy chirp to obtain time resolution within the probing period of the applied pulse in macromolecular crystallography was first proposed by Moffat in 2002 Faraday Discussions [34], shortly before the construction of the first XFEL. The energy chirp leads to streaking of time into reciprocal space in the diffraction pattern-because different wavelengths diffract to different locations on the detector, diffraction from the earliest energies is physically separated from diffraction caused by the energies arriving later in time. Through Laue indexing, an individual reflection can be assigned to the wavelength that stimulated it, and thus to its specific time within the pulse if there is an energy chirp. With sufficient bandwidth, a deconvolution of multiplicity would additionally be needed, such that the time-to-energy relation could still be extracted. Time-dependent information of the pump-probe experiment is therefore intrinsically present in individual images collected with chirped broadband pulses. The time interval across which structure amplitude differences are recorded is set by the chirp magnitude of the X-ray probe pulse. Moffat additionally proposed that if the pump pulse occurs within the probe, each image will also include unpumped reference structure factor amplitudes which will aid the scaling of time-resolved differences [34].

Here, we extend this method to XFEL pulses in order to obtain ultrafast time resolution with the availability of femtosecond energy-chirped hard X-ray pulses and consider the time resolution that could be obtainable. Several numerical simulation codes for SASE FELs have been developed to explore the effects of different beamline components on performance and to aid in the interpretation of experimental results [35-38]: they provide three-dimensional representations of the pulse by solving the FEL equations [39], which describe both the propagation of the electrons and the evolution of the radiation field. Calculation methods are constantly being improved. A recent version of GENESIS, one of the most widely used codes, is able to simulate the propagation and SASE of the entire electron 
beam through the undulator [40]. Pulse profiles computed in this way are presented here in order to simulate and assess the time dependence of experimental diffraction.

The aim of this work is thus to evaluate the time resolution, $\Delta t_{\text {res }}$, that would theoretically be achievable in a polychromatic XFEL experiment from considerations of physical parameters for protein crystallography. The X-ray pulse length, spectral bandwidth over time, and chirp magnitude determine the resolution and are obtained through simulations of the XFEL provided by SwissFEL. A ray-tracing simulation demonstrates the chirped diffraction patterns generated by the polychromatic XFEL pulse.

It has been shown that a $4 \%$ "extra pink" beam mode at SwissFEL will probe a large enough volume of reciprocal space to fully integrate multiple reflections [41]. As the polychromatic beam is chirped, it should be possible to identify which spots correspond to different energies and therefore to different points in time. Here, we consider a negative energy chirp, such that diffraction spots that appear at the leading edge of the pulse $\left(t_{\text {in }}\right)$ are stimulated by the highest energies. When evaluating full reflection integration, it is noted that, while the total spectral bandwidth that generates the polychromatic image is equal to the magnitude of the chirp (e.g., $4 \%$ ), we analyze the "instantaneous" frequency (IF) and "instantaneous" bandwidth $\left(\mathrm{BW}_{\mathrm{in}}\right)$ associated with every instance of the pulse that is obtained from Wigner-Ville distribution analysis of the simulated field [42,43]. The determination of IF in a pulse becomes useful when its spectral characteristics vary over time. The Wigner-Ville distribution (WVD) is a two-dimensional distribution of the signal in the time-frequency domain. Projection of the distribution on one axis results in either the temporal or the spectral structure of the pulse. The IF corresponds to the first moment of the WVD with respect to frequency [44,45], while $B W_{\text {in }}$ is defined as the standard deviation, or spread of frequencies, present at a given time [46].

The shortest resolvable time interval $\left(\Delta \mathrm{t}_{\text {res }}\right)$ should be dictated by the "instantaneous duration" of $\mathrm{BW}_{\mathrm{in}}$. This is given by the time-bandwidth product $(\Delta v \Delta \mathrm{t}=0.44$ for a Gaussian pulse): the time duration obtained from such time-bandwidth product corresponds to the minimum value at which a pulse with specific FWHM can theoretically be fully compressed. The bandwidth of the SASE pulse is increased relative to that of the contributions of individual spikes in a way that is analogous to how the experimental bandwidth of optical pulses can be expanded by adding together multiple optical sources each with a different carrier frequency [47]. The spectral width of a single isolated SASE spike at $9 \mathrm{keV}$ has been recorded to be $\approx 10 \mathrm{eV} \mathrm{[48]} \mathrm{at} \mathrm{LCLS,} \mathrm{which,} \mathrm{through} \mathrm{the} \mathrm{time-bandwidth} \mathrm{product,} \mathrm{corresponds}$ to a duration on the order of 200 as. The chirped pulse at SwissFEL consists of the superposition of "single spikes", varying in time and central frequency. The instantaneous bandwidth is determined by the pulse length and chirp of an individual spike. Therefore, the maximum time resolution that is possible for analyzing diffraction using chirped XFEL pulses is limited by the duration and chirp of the individual spike, which is analyzed from simulations here. Experimentally, based on the SwissFEL simulations presented, intervals shorter than 200 as will not be readily distinguishable with a SASE pulse, as the autocorrelation shows the intensity distribution within the 200-as duration. A coherence time shorter than 100 as has been discussed for harder X-ray $(24.8 \mathrm{KeV})$ and low bunch charge conditions at the European XFEL [49].

The time duration that each reflection is stimulated for will depend on the chirp and on the bandwidth required to fully integrate it $\left(\mathrm{BW}_{\text {req }}\right)$. The spot bandwidth is given as in [50]:

$$
\mathrm{BW}_{\text {req }}=(\eta+\gamma) \cot \theta
$$

where $\eta+\gamma$ is the effective mosaic spread (the sum of mosaicity and beam convergence) and $\theta$ is the Bragg angle. There is a dependence on resolution because the Ewald spheres diverge from the reciprocal space origin (Figure 1). 

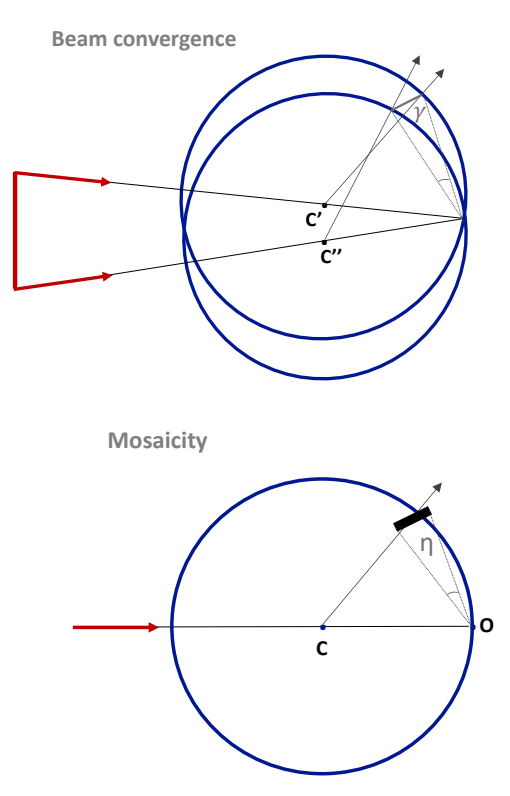

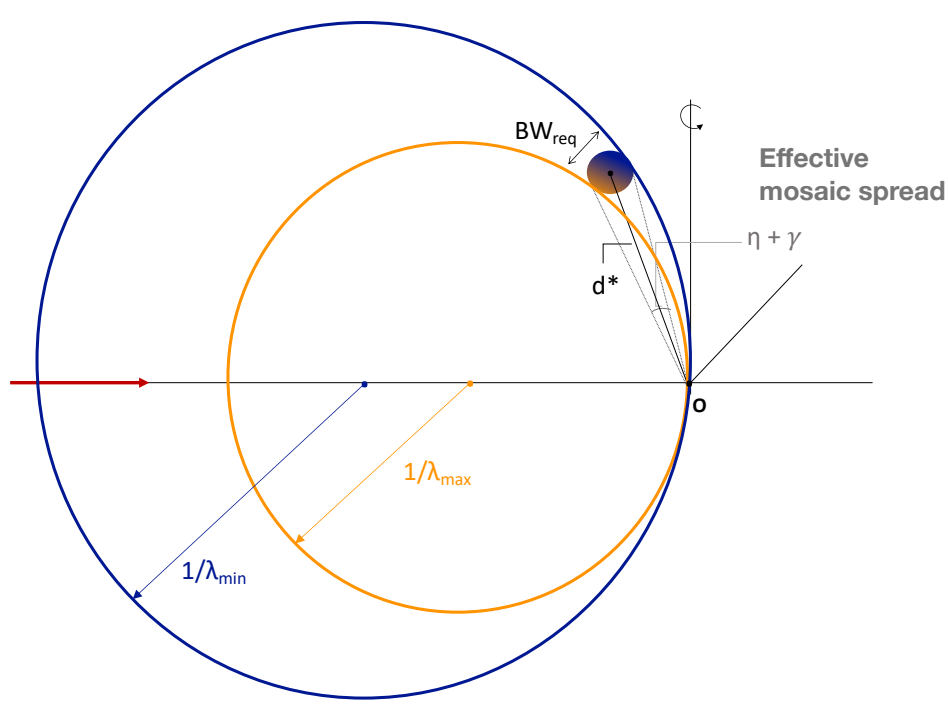

Figure 1. Effect of beam convergence $(\gamma)$ and mosaicity $(\eta)$ on the reflection bandwidth $\left(\mathrm{BW}_{\text {req }}\right)$. $\mathrm{BW}_{\text {req }}$ depends on the sum of $\gamma$ and $\eta$ and on the distance of the reciprocal lattice point from the reciprocal space origin $\left(d^{*}\right)$. The minimum $\left(\lambda_{\min }\right)$ and maximum $\left(\lambda_{\max }\right)$ wavelengths of the spot bandwidth are shown together with the energy gradient across the reflection.

\section{Results}

\subsection{SwissFEL Chirped Broadband Simulations}

Simulations of the SwissFEL pulse at three chirps $(1 \%, 2 \%$, and $4 \%)$ are presented in this paper (Figure 2). For the simulations, the results of measured beam parameters from the machine were used, when it was configured for large bandwidth operation [31]. This characterization of the electron beam was done at the injection point into the undulator, using a transverse deflector in order to obtain time-resolved beam parameters. We measured the current profile, the slice emittances, and the longitudinal phase space distribution. To the latter, we fitted a polynomial to determine the mean energy of the electron beam slices. With these parameters, we generated the input decks for the GENESIS simulation. Therefore, the results of the $2 \%$ chirp case actually reflect the existing machine settings, and the modeled pulse energy and spectral width agree well with the observed quantities. For the other two cases, the polynomial fit to the longitudinal phase space distribution was scaled by the factors 2.0 and 0.5 respectively, while keeping the other input parameters the same. This was done without demonstrating the feasibility of a different chirp at the machine. While it is straightforward to reduce the chirp, a larger chirp requires additional hardware, such as a dechirper, or a significant change in the compression configuration. Both approaches will be explored in upcoming machine studies at SwissFEL.

The simulation output contains the radiation power and phase as a function of the time within the time-window of the simulation. This is the basis for the calculation of the WVD, which then is used to calculate the time-resolved central frequency and the associated width of the chirped FEL pulse. From the WVD, the flux, IF, and instantaneous FWHM (FWHM $\left.{ }_{\text {in }}\right)$ can be extracted for the simulated chirps (Figure 2). We evaluate two conditions. Firstly, we consider the time intervals given by BW at different times in the pulse. Secondly, we assess the ratio between $\mathrm{BW}_{\text {in }}$ and $\mathrm{BW}_{\text {req }}$ to determine the expected integration time across resolutions. Among the available simulations, the largest chirp and bandwidth of $4 \%$ is expected to result in the best time resolution and was thus chosen for the following analysis. The values for IF and $\mathrm{FWHM}_{\text {in }}$ vary significantly over the course of the pulse 
(Figure 2), which means that the two points above need to be evaluated separately for different time bins. For calculations, only the central 20-fs of the WVD (between 52 and $72 \mathrm{fs}$ ) were included, as this is where the flux is concentrated (Figure 3). The early and late times contribute only very weakly to the total pulse intensity. This slicing reduces the available chirp from $4 \%$ to approximately $1.5 \%$, which is the realistically usable chirp. A short-range "single-shot" autocorrelation of this part of the SwissFEL simulation (Figure 3d) shows that the width of a single spike at SwissFEL is expected to be on the same range as at LCLS (200 as).

(a)

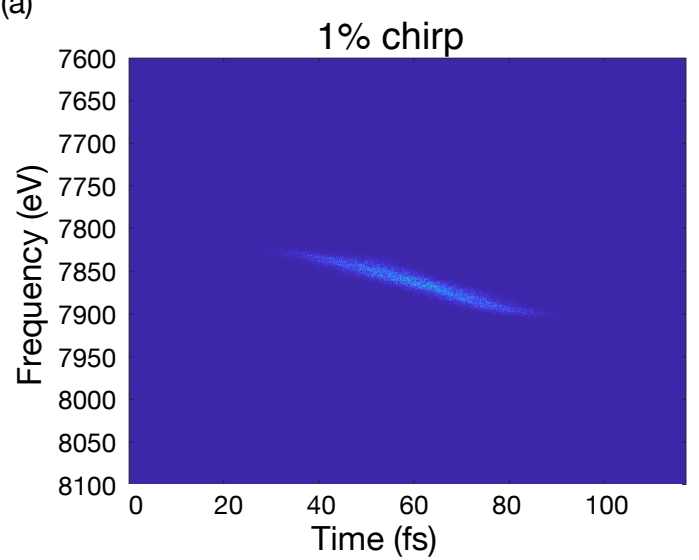

(c)

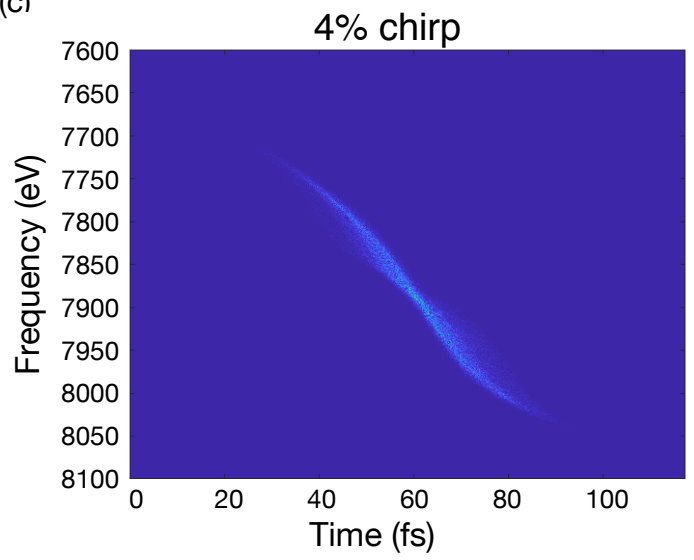

(e)

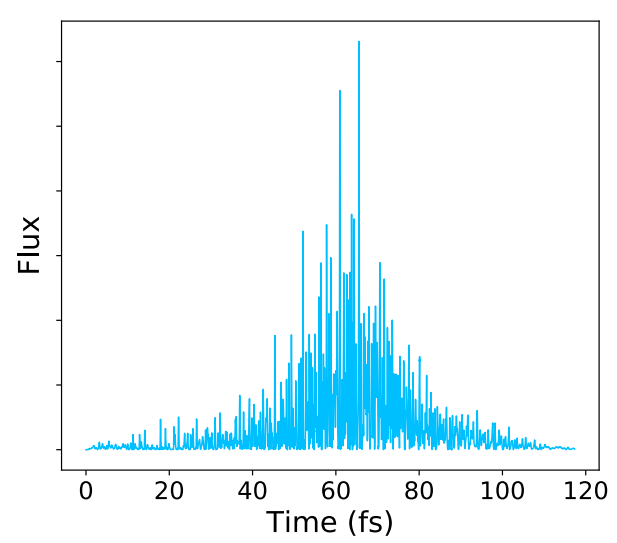

(b)

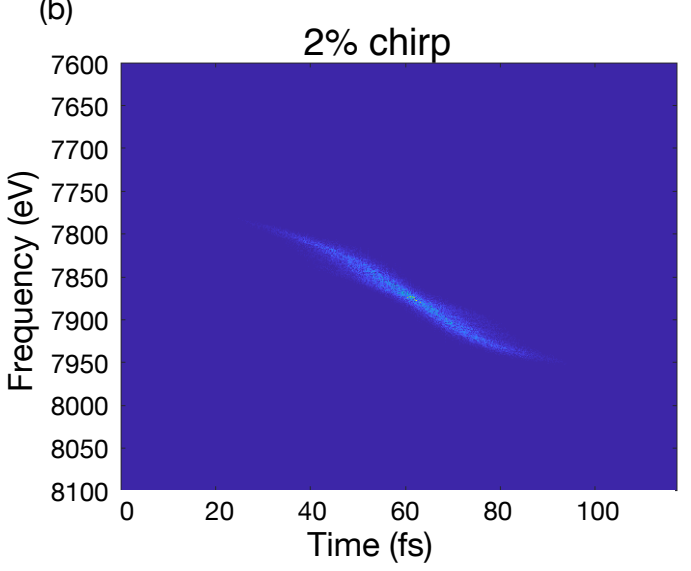

(d)

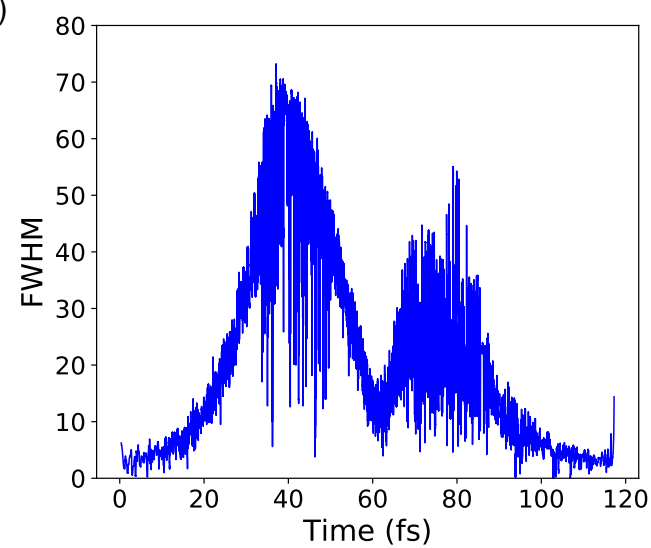

(f)

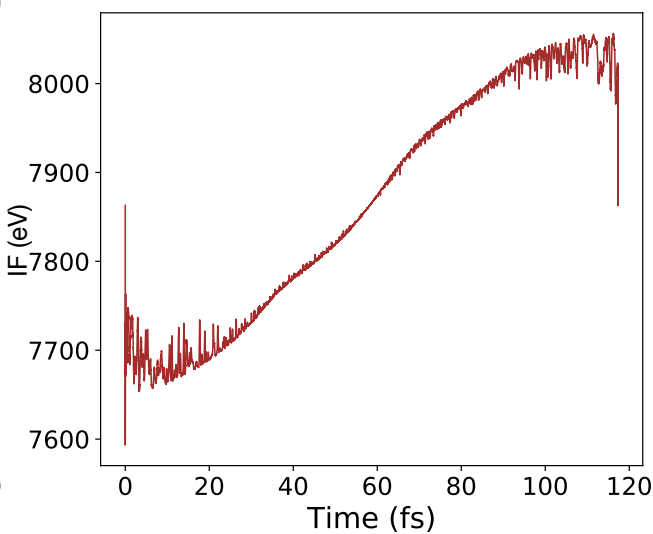

Figure 2. SwissFEL pulse characterization. Wigner-Ville distribution (WVD) for three available chirps: (a) $1 \%$ (b) $2 \%$, and (c) $4 \%$. (d,e,f) pulse characterization of the entire $120-$ fs $4 \%$ chirp SwissFEL pulse provided by analysis of the WVD. Instantaneous full width half maximum (FWHM in $)(\mathbf{d})$ flux (e) and IF (f) values are plotted. The frequency chirp is observable in the IF increase over time and the FWHMin is seen to change across the pulse. The highest frequencies are the first to arrive at the sample. 
(a)

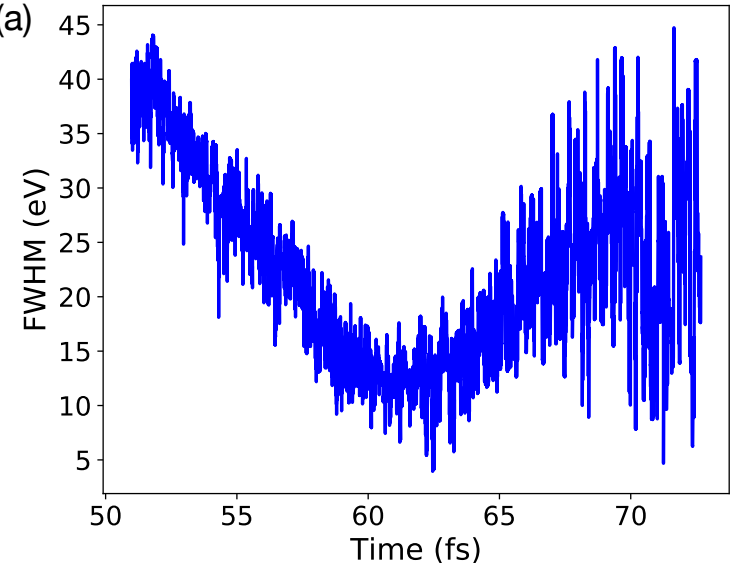

(c)

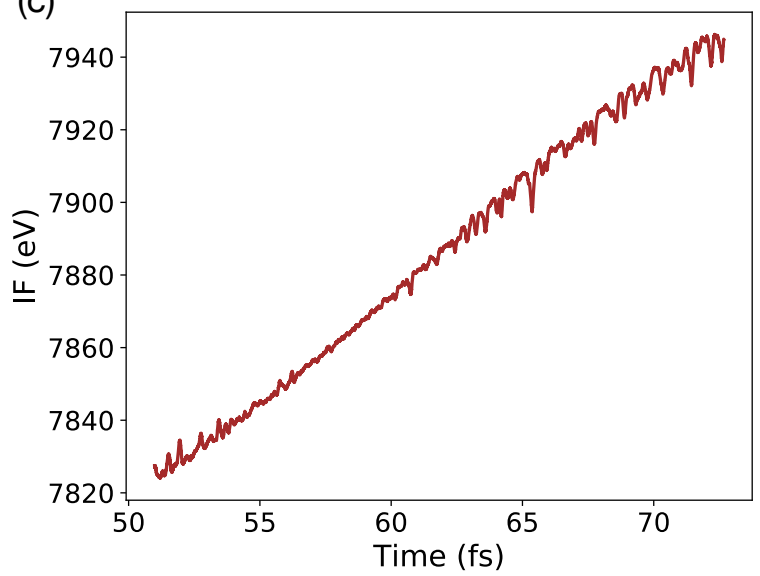

(b)

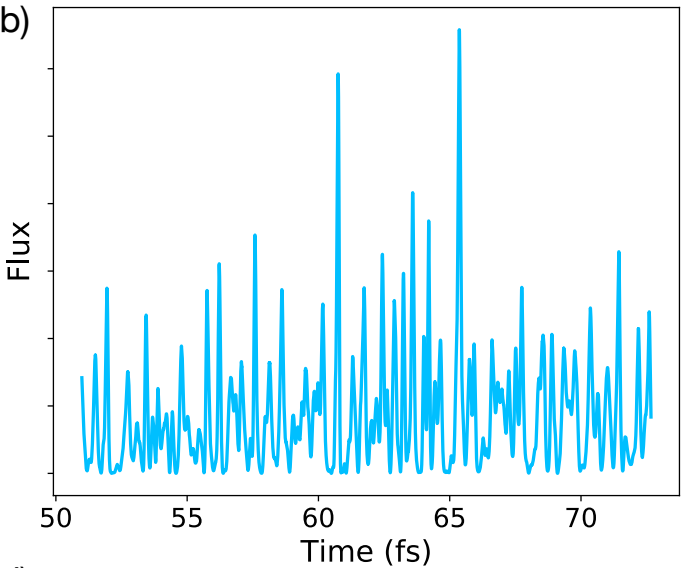

(d)

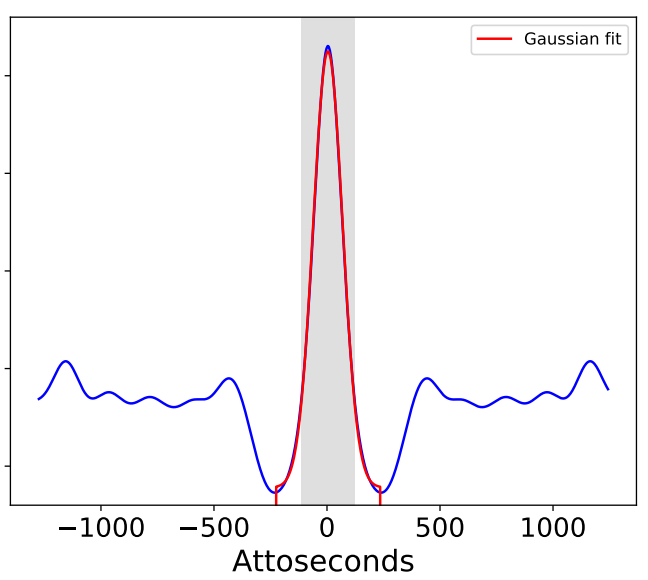

Figure 3. Central slicing of the pulse with $4 \%$ chirp. (a-c) respectively plot the $\mathrm{FWHM}_{\mathrm{in}}$, flux, and IF values when the pulse is sliced at these central 20-fs. The flux is constant across this central slice and the energy chirp is reduced to $\approx 1.5 \%$. The $\mathrm{FWHM}_{\text {in }}$ fluctuates between $40-10 \mathrm{eV}$. (d) Short-range "single-shot" autocorrelation of the central 20-fs of the pulse: the SASE spike width is on the order of 200 as.

\subsection{Determination of $\Delta t_{\text {res }}$}

The central 20-fs of the WVD (between 52 and $72 \mathrm{fs}$ ) were split into 20 bins of 1-fs duration, each with its mean IF and $\mathrm{FWHM}_{\text {in }}$. For each bin, $\mathrm{BW}_{\text {req }}$ was calculated at resolutions between 0.9 and $10 \AA$ and for effective mosaic spread values between $0.05-0.5^{\circ}$ using Equation 1 (Figure $4 \mathrm{a}$ ). As mentioned above, the effective mosaic spread is a sum of the beam convergence and mosaicity contributions: at XFEL facilities, beam convergence at around $9 \mathrm{keV}$ ranges from a few microradians (on the order of $10^{-4}$ degrees) [51-53] for the unfocused beam, to tens of microradians if KB mirrors (e.g., $\approx 47 \mu \mathrm{rad} \approx 0.002^{\circ}$ [54]) or compound refractive lenses (e.g., $\approx 91 \mu \mathrm{rad} \approx 0.005^{\circ}$ [55]) are used for focusing. As this is considerably smaller than the mosaic spread of protein crystals, the latter is the determining factor. The range of mosaic spread used here considers very low mosaicity values, such as those from crystals of the photoactive yellow protein (PYP, $\eta \approx 0.04^{\circ}[56]$ ), as well as values up to ten times larger. From the $\mathrm{BW}_{\text {req }}$ of a reflection, it is also possible to calculate the amount of time it is stimulated for (Figure $4 \mathrm{~b}$ ). The $\Delta \mathrm{t}_{\mathrm{IF}} / \Delta \mathrm{t}$ for the chirp is $5.6 \mathrm{eV} / \mathrm{fs}$, the required $\Delta \mathrm{t}_{\mathrm{IF}}$ is given by $\mathrm{BW}_{\text {req, }}$ and $\Delta \mathrm{t}$ is solved for. At mosaicity $=0.5^{\circ}$, low-resolution reflections are expected to spend up to $8 \mathrm{fs}$ in reflecting condition. On the other hand, high-resolution reflections at low mosaicity values will be fully "instantaneously" integrated by BW $\mathrm{BW}_{\text {in }}$ (Figure $4 \mathrm{~b}, \mathrm{c}$ ). Figure 5 shows the predicted integration for a lowand a high-resolution reflection during the same interval in the pulse along with the linear chirp in IF. The $1.5 \AA$ reflection is fully integrated in 500 as, while the $5 \AA$ one is calculated to remain in reflecting condition for $2 \mathrm{fs}$. These time durations are dictated by $\mathrm{BW}_{\text {req }}$ for the individual reflections and by the 
mean $\mathrm{BW}_{\text {in }}$ in the time bin. Time durations were calculated from $\mathrm{BW}_{\text {in }}$ values through time-bandwidth products. The instantaneous durations given by the mean $\mathrm{FWHM}_{\text {in }}$ of each time bin specify the formal limit to the time resolution and vary between 50 and 150 as (Figure 6a). These values were calculated using a time-bandwidth product of 0.44 and therefore underestimate the pulse duration as the chirp of the single spike is not included in their calculation: in the presence of spectral phase, the spike duration is correspondingly longer [48]. Figure $4 \mathrm{c}$ shows the ratios between $\mathrm{BW}_{\text {req }}$ and the available $\mathrm{BW}_{\text {in }}$ given by the WVD. As expected, ratios decrease as a function of resolution, with values all below 0.4 at resolutions lower than $4 \AA$. From these ratios, the number of energy points per reflection (that is, how many $\mathrm{BW}_{\text {in }}$ are needed to integrate it) was derived (Figure $6 \mathrm{~b}$ ). Realistically, many of the energy contributions will overlap on the diffraction pattern, so the number of points per reflection was only calculated for bins with $\mathrm{BW}_{\mathrm{in}} / \mathrm{BW}_{\text {req }} \geq 0.2$, setting a limit of 5 energy/time points per reflection. Bins with $B W_{\text {in }} / \mathrm{BW}_{\text {req }}<0.2$ were automatically assigned a value of 10 energy/time points per reflection to indicate that there should be more than 5 time points per reflection but these are not expected to be resolved. Figure $6 \mathrm{~b}$ shows values that range from 1 to 10 in the $0-5 \AA$ range. All bins at resolutions lower than $5 \AA$ were assigned a value of 10 and are not shown in the plot. A ray-tracing simulation was carried out to evaluate the images that would be generated by the pulse and the observable gradients across reflections.

(a)

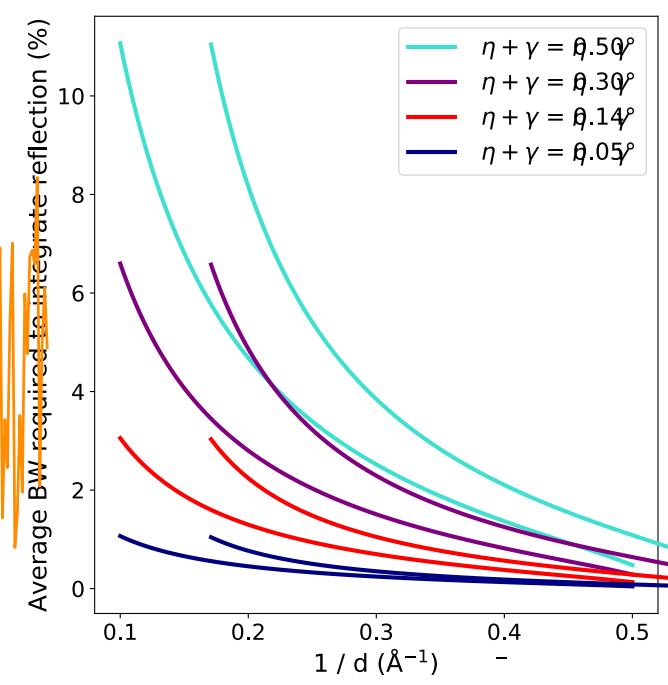

(b)

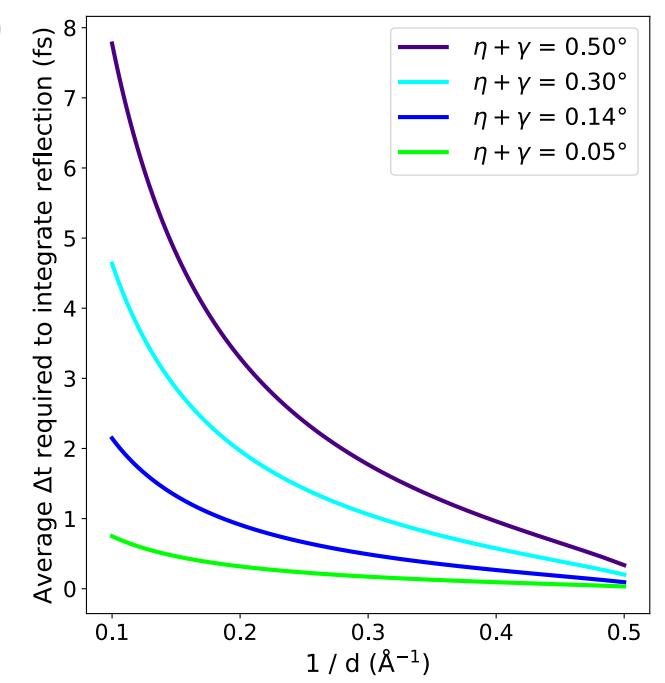

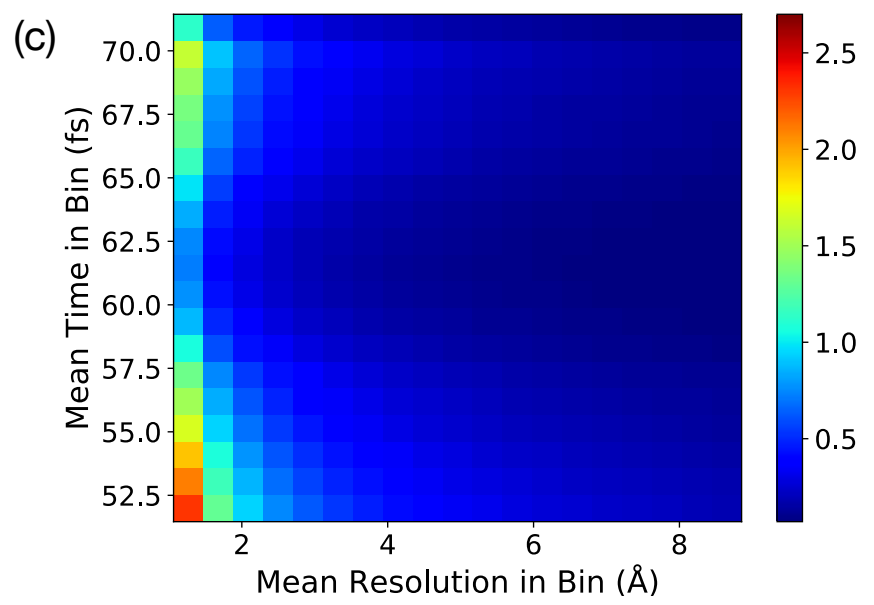

Figure 4. Requirements for full reflection integration. (a) Calculated values of $\mathrm{BW}_{\text {req }}$ as a function of resolution for four effective mosaic spreads $(\eta+\gamma)$. (b) Time interval required to integrate a reflection at different resolutions for four effective mosaic spreads. (c) Ratio of available to required bandwidths for each 1 -fs time bin at different resolutions. 

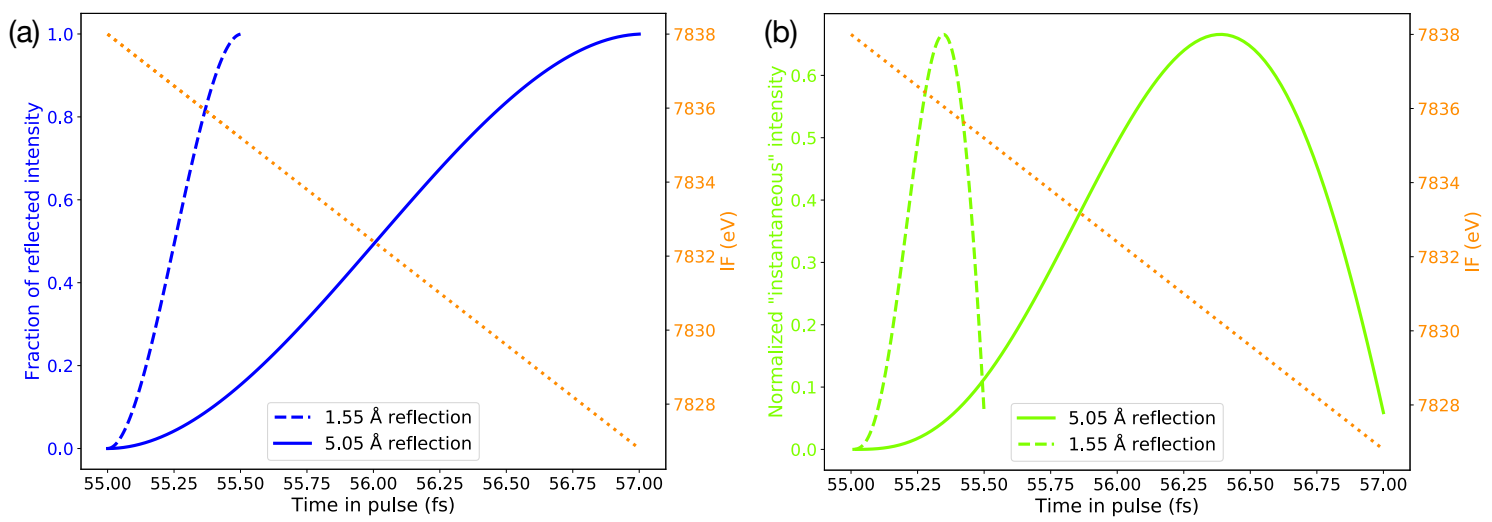

Figure 5. Predicted integration of two reflections at different resolutions for $0.3^{\circ}$ mosaicity between 55 and $57 \mathrm{fs}$ after arrival of the pulse at the sample. The mean instantaneous bandwidth in this interval is $22 \mathrm{eV}$. The decrease in IF due to the linear chirp across the interval is also shown. (a) Partiality as a function of time (b) "Instantaneous intensity" as a function of time normalized to the partiality.

(a)

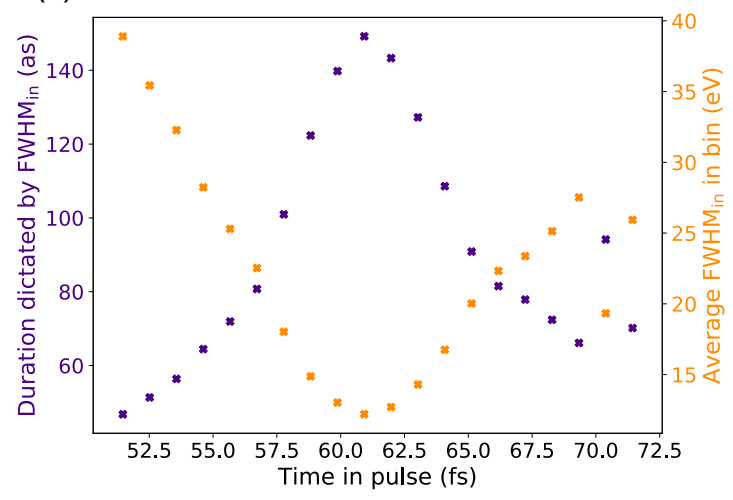

(b)

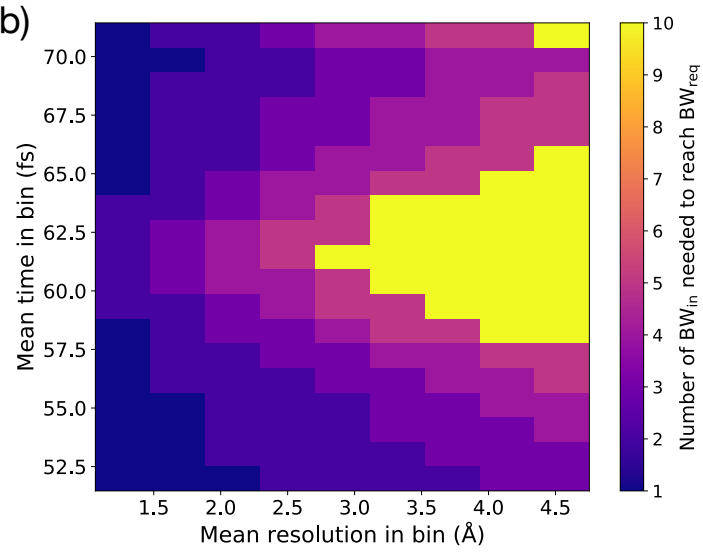

Figure 6. Properties set by $\mathrm{BW}_{\mathrm{in}}$. (a) Instantaneous duration set by the mean $\mathrm{FWHM}_{\text {in }}$ for each time bin. These intervals are all smaller than the 200 -as set by the single SASE spike width. (b) Energy/time points expected per reflection at different times in the pulse and different resolutions (up to $5 \AA$ ). All bins at resolutions lower than $5 \AA$ were assigned a value of 10 and are not shown in the plot.

\subsection{Ray-Tracing Simulation and Time Mapping}

The program SIM-MX by Kay Diederichs [57] was used to simulate still diffraction images from a single PYP crystal (2PHY.pdb) with experimentally determined parameters such as unit cell dimensions and mosaic spread [58]. The full list of input values for the program can be found in Table 1 and the definition of each is described in the original publication [57]. As stills are not implemented in SIM-MX, these were simulated by using a very small oscillation range $\left(0.01^{\circ}\right)$. One "still" image was generated for each of the 20 time bins by tracing 10,000 rays per frame: the simulation wavelength and its standard deviation were given by the mean IF and $\mathrm{FWHM}_{\mathrm{in}}$ of each bin. These stills were then summed to obtain a diffraction pattern for the polychromatic, chirped pulse. The reflections within this image can be tagged according to their energy, and thus according to their time of arrival at the crystal. In Figures 7 and 8, intensities on the diffraction pattern are color-coded based on the energy that stimulated them, which allows one to relate them to their time within the pulse. Diffraction images were first simulated using the $1.5 \%$ chirped central slice of the SwissFEL pulse. A second simulation was then run with a hypothetical $10 \%$ chirp to emphasize the achievable effect. The diffraction patterns show new reflections appearing during the duration of the pulse as well as low-resolution reflections that contain multiple energy contributions (Videos S1-S3). The observable intensity gradients are significantly enhanced by the higher chirp (Figure 8). 

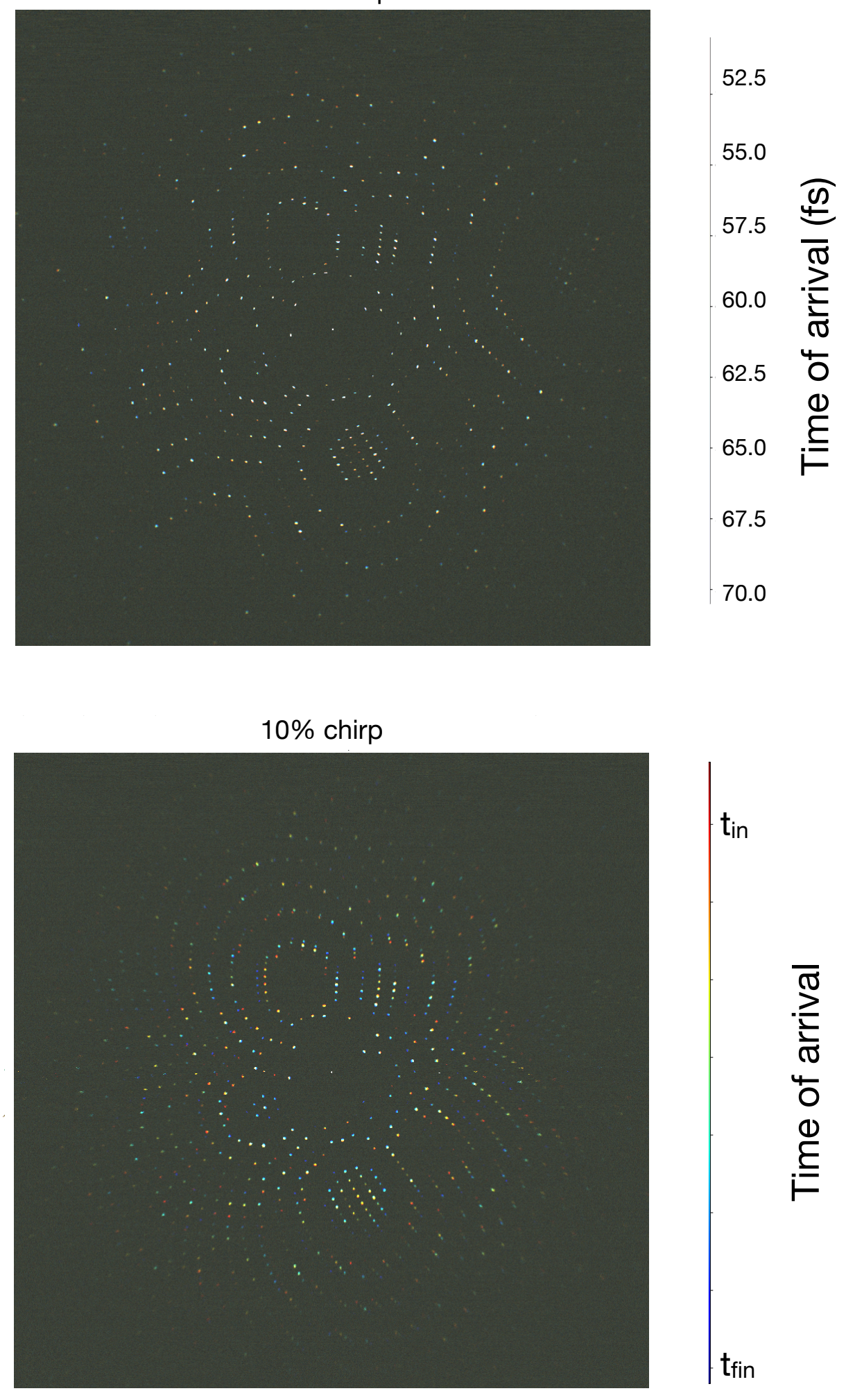

Figure 7. Chirped pulse diffraction. Simulated diffraction patterns for the central 20-fs of the SwissFEL pulse and for a hypothetical $10 \%$ chirp. Different energy contributions are colored based on their time of arrival for the smaller chirp. As a simulation for $10 \%$ chirp at SwissFEL is not available, the streaking effect is shown without specific time assignments. The simulated diffraction extends to a resolution of $1.5 \AA$. 

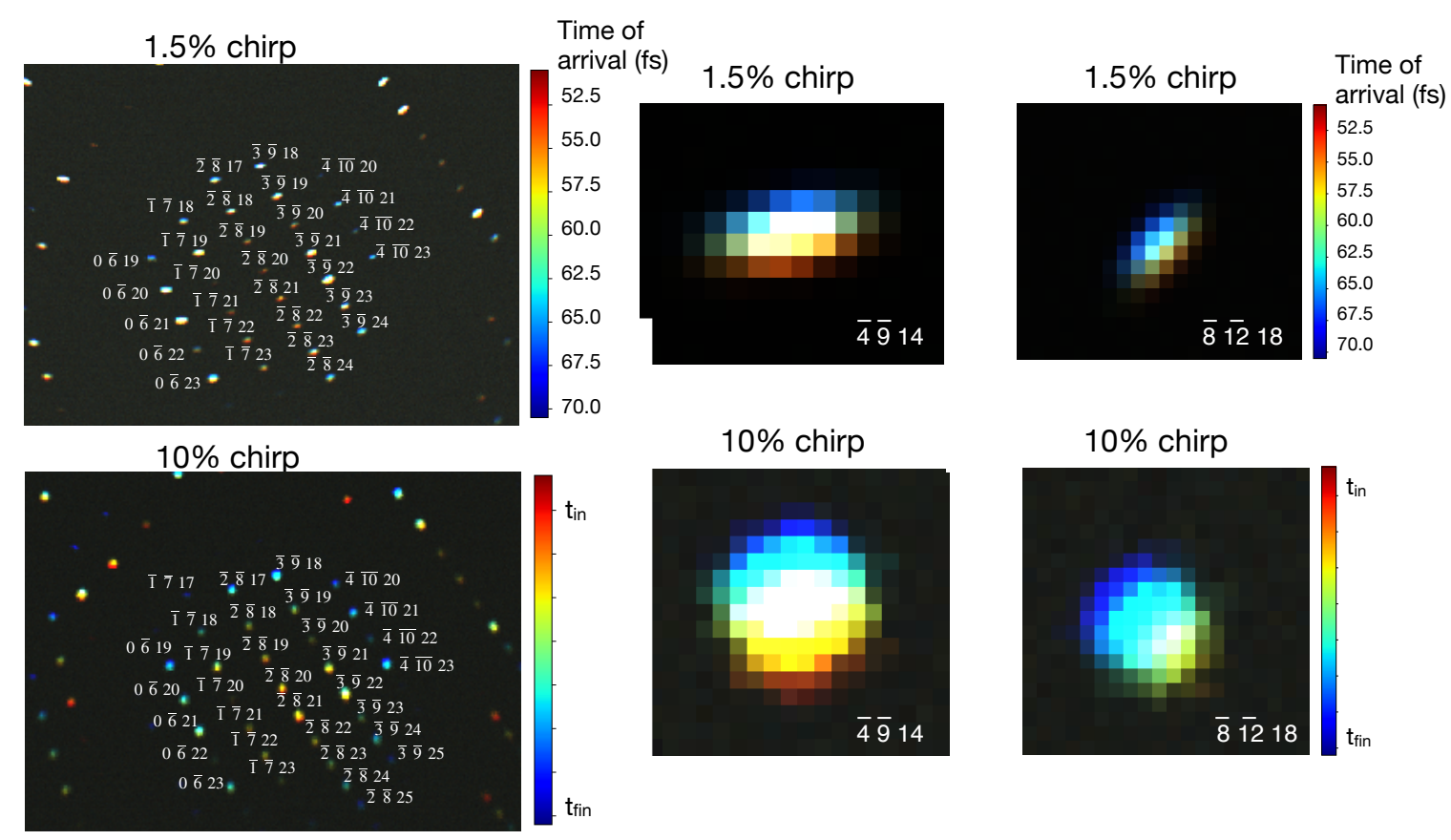

Figure 8. Comparison of the time/energy streaking in space in the same reflections at two different chirps (top panels against bottom panels). Reflections are labeled with their Miller indices.

Table 1. Input parameters for SIM-MX simulations.

\begin{tabular}{llll}
\hline Input Parameter & \multicolumn{3}{c}{ Value } \\
\hline UNIT_CELL_A-AXIS & -41.745625 & -19.906780 & 47.598270 \\
UNIT_CELL_B-AXIS & 24.133776 & -43.948139 & -43.482101 \\
UNIT_CELL_C-AXIS & 31.530138 & -7.105332 & 24.681583 \\
EXPOSURE FACTOR & 1 & & \\
GAIN & 1 & & \\
BACKGROUND & 20 & & \\
BIG_CRYSTAL & TRUE & & \\
BEAM_STDDEV & 0.1 & 0.1 & 0.04 \\
CELL_STDDEV & 0.04 & 0.04 & 0.04 \\
ORIENTATION_STDDEV & 0.04 & 0.04 & \\
OSCILLATION_RANGE & 0.01 & & \\
DETECTOR_DISTANCE & $59.1 \mathrm{~mm}$ & & \\
INCIDENT_BEAM_DIRECTION & 0.0 & 0.008727 & 0.99999619 \\
\hline
\end{tabular}

\section{Discussion}

The analysis presented here concludes that, given the polychromatic chirped XFEL pulse currently available at SwissFEL, the instantaneous bandwidths throughout the pulse correspond to time intervals between $\approx 50-150$ as. In principle, this matches the shortest possible time that high-resolution reflections can spend in stimulated conditions (Figure 5). In order to analyze diffraction to the maximum possible time resolution determined by the instantaneous bandwidth, the precise position in the chirped pulse needs to be determined by fully resolving the X-ray energy for each reflection, with additional deconvolution of rare multiples. This would rely on stationary analysis with full knowledge of the chirped pulse spectral parameters. The intensity profile would need to be known as wavelength normalization from polychromatic data requires multiple symmetry-related reflections to be measured which are stimulated by different energies to derive a $\lambda$-curve. For spontaneous $X$-ray sources, they are typically fitted to Chebyshev polynomials [59-63]. Time-resolving structure factor amplitudes within the chirped pulse therefore prevents $\lambda$-curve fitting. The chirp magnitude may additionally contribute to the experimental time resolution, as between $2 \mathrm{fs}$ and $8 \mathrm{fs}$ elapse for the 
instantaneous frequency to be modified by the magnitude of the instantaneous bandwidth (Figure 3). The practical limit to the time resolution, purely from the point of X-ray diffraction observation, will therefore be affected by the ability to determine the X-ray energy for each reflection, which reports on the progression of time within the chirped XFEL pulse. Practically, a stationary analysis would find a wavelength assignment with high accuracy. While the chirp magnitude from the simulation remains relatively constant at approximately $\approx 5 \mathrm{eV} / \mathrm{fs}$ in the central part of the pulse that contains most intensity (Figure 3c), the instantaneous bandwidth varies between values of $40 \mathrm{eV}$ and $10 \mathrm{eV}$ (Figure 3a). Therefore, a resolution of 200 as would require experimental determination of a change of $\approx 1 \mathrm{eV}$ in the instantaneous frequency from the integrated intensities. Considering the spectral structure of XFEL pulses, there may be limits arising from signal-to-noise to fully exploit the time-resolved analysis of chirped-pulse crystallography.

From the simulations performed, gradients across individual low-resolution reflections are observable as well as different high-resolution reflections integrated by different energies over the course of the single pulse. It is clear that an increase in chirp magnitude allows a better distinction of specific energies: maximizing this parameter will become crucial when addressing the signal-to-noise ratio in an experimental setting. While this result is based solely on the properties of the XFEL pulse and reciprocal space, there are still several limitations that currently lower the experimentally achievable time resolution from its theoretical limit. The main limiting factors to $\Delta \mathrm{t}_{\text {res }}$ will be the duration of the pump pulse, the group velocity mismatch, and the pump-probe timing at the beamline. Optical pulses used for protein excitation at XFELs up to now have been on the order of $100 \mathrm{fs}$. In addition, the absolute pump-probe time at the interaction point in the experiment, determined through a specific timing tool in SFX experiments, carries an uncertainty of 30-50 fs [64-66]. Development of hollow core fibers for ultrafast laser pulse generation [67-69] has enabled production of single-cycle pulses, with a duration of only a few femtoseconds, or attosecond half-cycle pulses $[47,70-72]$ that have also been used for ultrafast pump-probe spectroscopy experiments [73,74]. The implementation of such pulses in pumping sample at SFX experiments would improve the earliest observable time point after excitation. Furthermore, Moffat's original discussion proposed that the pump pulse occur within the X-ray probe, so that each image would contain an internal dark control as well as multiple time points. Laser pulses with attosecond or few-femtosecond durations will be a requirement to have optical excitation occur within the 100-fs XFEL pulse.

In the context of using shorter pump pulses and with the idea of pursuing femtosecond time resolution as well as Moffat's original proposal [34] of pumping within the probe pulse, chromatic dispersion of the laser light has to be considered: there is a physical limit dictated by the material dispersion of the optical pump pulse when propagating through the protein crystal and the delivery matrix or solution. Chromatic dispersion is larger in pulses with large bandwidths, and so will become significant if few-cycles ultrashort lasers are used for pumping; the fact that the protein sample is excited by the pump is also important, as group velocity dispersion (GVD) behavior differs at absorption [75]. Though crystal birefringence results in an orientation dependence of the GVD value [76], its contribution is not further considered here. Figure 9 shows final pulse durations given a range of extremely short femtosecond pulses and different group delay dispersion (GDD) values. The output pulse is calculated with the following standard relationship [77]:

$$
t_{\text {out }}=\frac{\sqrt{t_{\text {in }}^{4}+16(\ln 2)^{2} \mathrm{GDD}^{2}}}{t_{\text {in }}},
$$

where GDD is the GVD multiplied by sample thickness and $t_{\text {in }}$ is the initial pulse duration. As there are (to our knowledge) no published GVD values for visible light absorbing protein crystals, we used the concentration dependence of the GVD for Rhodamine 6G dye solution near its 600-nm absorption resonance [78] to estimate the GDD for a protein microcrystal: for a 5- $\mu \mathrm{m}$ thick crystal with $60-\mathrm{mM}$ chromophore concentration, the GVD is scaled to $2258 \mathrm{fs}^{2} / \mathrm{mm}$ and the GDD is calculated to be $11.29 \mathrm{fs}^{2}$. 
This yields an output pulse of $10.85 \mathrm{fs}$, which is more than three times the 3-fs input pulse. The method of sample delivery will also add to chromatic dispersion: the stretching introduced by a $5-\mu \mathrm{m}$ GDVN nozzle jet (GDD $=0.20 \mathrm{fs}^{2}$ if the GVD of water is taken to be $39 \mathrm{fs}^{2} / \mathrm{mm}$ at $600 \mathrm{~nm}$ [79]) is on the order of a few attoseconds, so not large for our purposes. Additional stretching, however, becomes significant with delivery methods that introduce more liquid in the beam path, such as the drop-on-demand injector [80]: this produces droplets approximately $170-\mu \mathrm{m}$ in diameter that are expected to double the duration of a 3-fs pulse (Figure 9-table). The stretching of the optical pump is clearly relevant for visible light absorbing protein crystals and will therefore have to be evaluated depending on the experimental conditions (such as the distribution of crystal sizes and the injection method available). The same considerations apply to third-order dispersion (TOD), which can contribute to stretching as much as GVD at such short pulse durations.

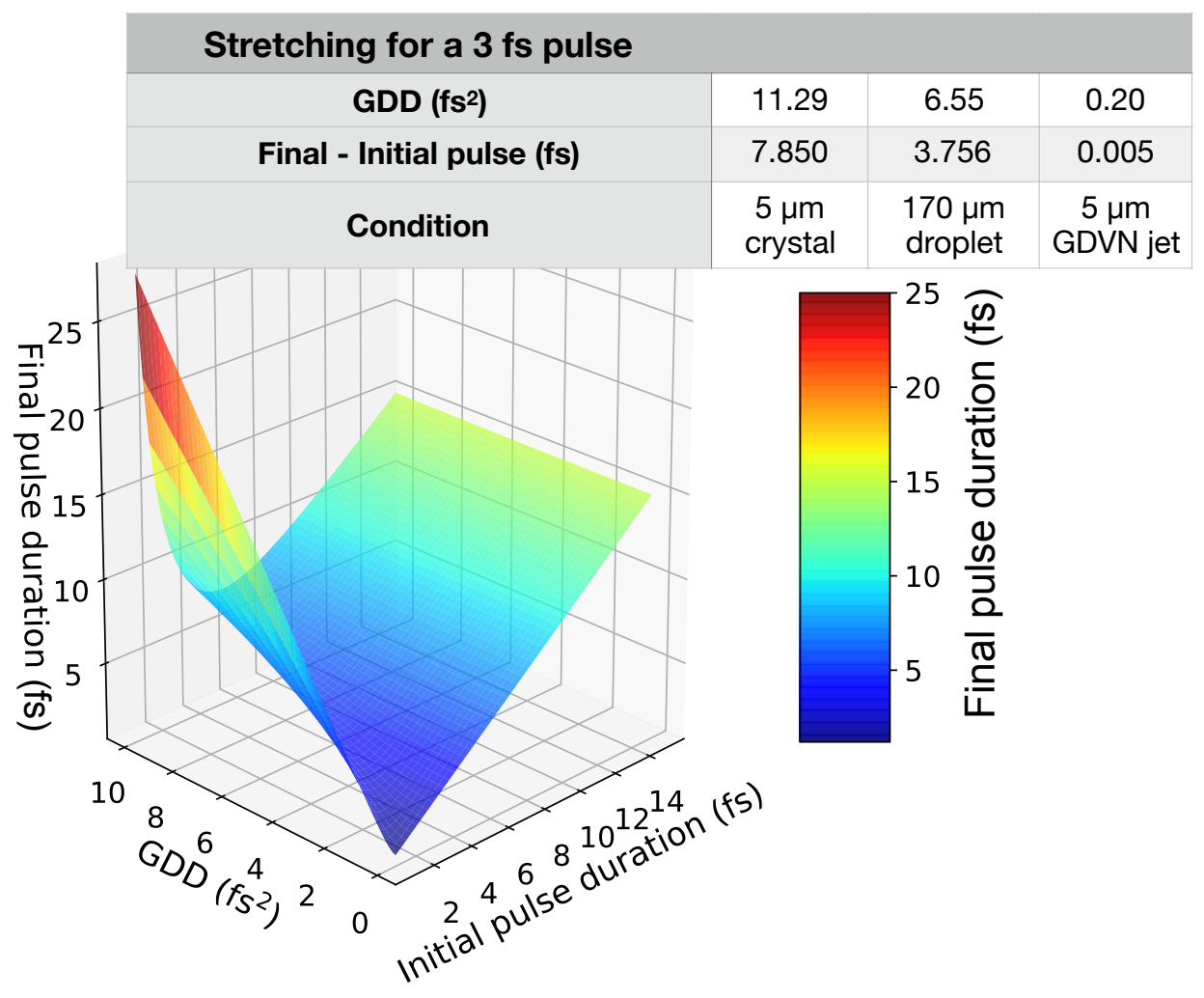

Figure 9. Chromatic dispersion effect. Calculated stretching of a femtosecond optical pulse given a range of group dispersion delay (GDD) values. The table shows stretching values for a 5- $\mu \mathrm{m}$ GDVN jet $\left(\mathrm{GDD}=0.20 \mathrm{fs}^{2}\right)$, a $170-\mu \mathrm{m}$ droplet $\left(\mathrm{GDD}=6.50 \mathrm{fs}^{2}\right)$, and a $5-\mu \mathrm{m}$ crystal $\left(\mathrm{GDD}=11.29 \mathrm{fs}^{2}\right)$.

Additionally, the group velocity of the optical pump pulse will differ from that of the X-ray probe in a protein crystal: the X-rays will propagate with a refractive index of 1 but a larger refractive index is associated with the optical pulse $(\approx 1.2-1.4$ for proteins at crystal growth concentrations [81,82]), resulting in group velocity mismatch (GVM) between the two. Larger crystals will increase this effect, as they introduce a larger path length for the pulses. Figure 10 plots the expected added delay of the optical pump for a distribution of crystal thicknesses at different possible protein crystal refractive indexes: for a $2-\mu \mathrm{m}$ crystal and $\mathrm{n}=1.3$, for example, the achievable time resolution cannot be higher than $2 \mathrm{fs}$, as this is the amount of time by which the pump will be slowed down compared to the probe pulse. The added delay is calculated by multiplying the GVM with the crystal thickness. The GVM is given by the pump and probe group velocities ( $v_{\text {pump }}$ and $\left.v_{\text {probe }}\right)$ in the crystal and therefore by their refractive indexes:

$$
\mathrm{GVM}=\frac{1}{v_{\text {pump }}}-\frac{1}{v_{\text {probe }}}=\frac{\mathrm{n}_{\text {pump }}}{c}-\frac{\mathrm{n}_{\text {probe }}}{c} .
$$


A final point to consider is the self-focusing that occurs if the pulse power exceeds a critical power, $P_{\mathrm{cr}}$. The nonlinearity effects that result from self-focusing can lead to a total collapse of the beam. While for $\mathrm{CW}$ lasers there is a mathematical relationship to calculate $P_{\mathrm{cr}}$ from the nonlinear refractive index of a medium, this cannot be used accurately for ultrashort pulses [83] so we cannot predict a specific threshold for self-focusing. This effect is, however, observed regularly with femtosecond pulsed lasers [84-87] and is expected at the gigawatt peak powers reached by lasers generated through hollow core fiber compression. In a successful experiment, these incredibly high peak powers will have to be contained to avoid self-focusing, beam filamentation, as well as nonlinear absorption effects in the sample.

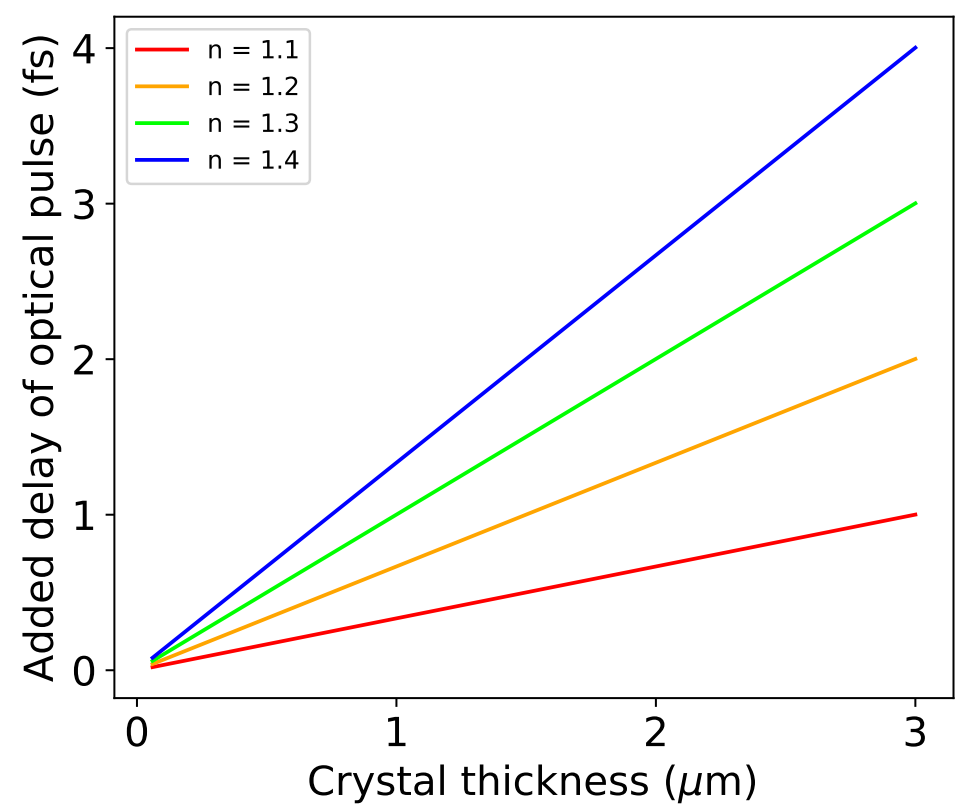

Figure 10. Group velocity mismatch. Added delay of the optical pump pulse compared to the X-ray probe due to group velocity mismatch when propagating through a protein crystal. The effect is plotted as a function of crystal thickness and for different possible refractive indexes of protein crystals.

\section{Materials and Methods}

Simulations for the SwissFEL pulse were done using GENESIS $[35,40]$. Ray-tracing simulations were done using the SIM-MX software [57].

\section{Conclusions}

The operation of a polychromatic XFEL source with new chirping capabilities introduces the possibility of performing SFX experiments with sub-femtosecond time resolution via a time-to-energy mapping of the protein diffraction patterns. This could further our understanding of protein dynamics by allowing, for example, visualization of conical intersections, or be applied to investigate radiation damage in protein crystals if the X-rays are used as both the probe and as a damage-inducing pump. A number of technical obstacles lie in the way of this theoretical result, yet ongoing improvements in laser and beamline technologies suggest that the experiment presented here has high chances of being possible in the near future. The ability to maximize the X-ray frequency chirp and to accurately time the pump and probe pulses will be especially relevant in this regard. New algorithms that accept large bandwidths in processing of serial crystal data (such as the PinkIndexer library implemented in CrystFEL [88]) could then be applied for the indexing and wavelength assignment of the diffraction images generated. 
Supplementary Materials: The following are available online at http:/ /www.mdpi.com/2076-3417/10/7/2599/ s1.

Author Contributions: J.J.v.T. conceived the experiment. S.R. performed the SwissFEL pulse simulations. A.F. performed the calculations and ray-tracing simulations. K.N. introduced the discussion on group velocity mismatch. All authors have read and agreed to the published version of the manuscript.

Funding: We acknowledge funding from the Imperial College President's PhD Scholarship and the Biotechnology and Biological Sciences Research Council (BBSRC) (No. BB/P00752X/1).

Acknowledgments: We thank Christopher Milne for discussion.

Conflicts of Interest: The authors declare no conflict of interest.

\section{References}

1. Pande, K.; Hutchison, C.D.; Groenhof, G.; Aquila, A.; Robinson, J.S.; Tenboer, J.; Basu, S.; Boutet, S.; DePonte, D.P.; Liang, M.; et al. Femtosecond structural dynamics drives the trans/cis isomerization in photoactive yellow protein. Science 2016, 352, 725-729. doi:10.1126/science.aad5081. [CrossRef] [PubMed]

2. Young, I.D.; Ibrahim, M.; Chatterjee, R.; Gul, S.; Fuller, F.D.; Koroidov, S.; Brewster, A.S.; Tran, R.; Alonso-Mori, R.; Kroll, T.; et al. Structure of photosystem II and substrate binding at room temperature. Nature 2016, 540, 453-457. doi:10.1038/nature20161. [CrossRef] [PubMed]

3. Suga, M.; Akita, F.; Sugahara, M.; Kubo, M.; Nakajima, Y.; Nakane, T.; Yamashita, K.; Umena, Y.; Nakabayashi, M.; Yamane, T.; et al. Light-induced structural changes and the site of $\mathrm{O}=\mathrm{O}$ bond formation in PSII caught by XFEL. Nature 2017, 543, 131-135. doi:10.1038/nature21400. [CrossRef] [PubMed]

4. Coquelle, N.; Sliwa, M.; Woodhouse, J.; Schirò, G.; Adam, V.; Aquila, A.; Barends, T.R.; Boutet, S.; Byrdin, M.; Carbajo, S.; et al. Chromophore twisting in the excited state of a photoswitchable fluorescent protein captured by time-resolved serial femtosecond crystallography. Nat. Chem. 2018, 10, 31-37. doi:10.1038/NCHEM.2853. [CrossRef]

5. Arnlund, D.; Johansson, L.C.; Wickstrand, C.; Barty, A.; Williams, G.J.; Malmerberg, E.; Davidsson, J.; Milathianaki, D.; DePonte, D.P.; Shoeman, R.L.; et al. Visualizing a protein quake with time-resolved X-ray scattering at a free-electron laser. Nat. Methods 2014, 11, 923-926. doi:10.1038/nmeth.3067. [CrossRef]

6. Nango, E.; Royant, A.; Kubo, M.; Nakane, T.; Wickstrand, C.; Kimura, T.; Tanaka, T.; Tono, K.; Song, C.; Tanaka, R.; et al. A three-dimensional movie of structural changes in bacteriorhodopsin. Science 2016, 354, 1552-1557. doi:10.1126/science.aah3497. [CrossRef]

7. Nogly, P.; Weinert, T.; James, D.; Carbajo, S.; Ozerov, D.; Furrer, A.; Gashi, D.; Borin, V.; Skopintsev, P.; Jaeger, K.; et al. Retinal isomerization in bacteriorhodopsin captured by a femtosecond X-ray laser. Science 2018, 361, 1-15. doi:10.1126/science.aat0094. [CrossRef]

8. Dunne, M. LCLS Strategic Facility Development Plan; Technical Report; SLAC National Accelerator Laboratory: Menlo Park, CA, USA, 2019.

9. Schneidmiller, E.A.; Yurkov, M. Photon Beam Properties at the European XFEL; Technical Report Report No. XFEL.EU TR-2011-006; Deutsches Elektronen-Synchrotron (DESY): Hamburg, Germany, 2011; doi:10.3204/DESY11-152. [CrossRef]

10. Yabashi, M.; Tanaka, H.; Ishikawa, T. Overview of the SACLA facility. J. Synchrotron Radiat. 2015, 22, 477-484. doi:10.1107/S1600577515004658. [CrossRef]

11. Madey, J.M. Stimulated emission of bremsstrahlung in a periodic magnetic field. J. Appl. Phys. 1971, 42, $1906-1913$. doi:10.1063/1.1660466. [CrossRef]

12. Deacon, D.A.G.; Elias, L.R.; Madey, J.M.J.; Ramian, G.J.; Schwettman, H.A.; Smith, T.I. First Operation of a Free-Electron Laser. Phys. Rev. Lett. 1977, 38, 892-894. doi:10.1103/PhysRevLett.38.892. [CrossRef]

13. Bonifacio, R.; Pellegrini, C.; Narducci, L.M. Collective instabilities and high-gain regime in a free electron laser. Opt. Commun. 1984, 50, 373-378. doi:10.1016/0030-4018(84)90105-6. [CrossRef]

14. Kondratenko, A.M.; Saldin, E.L. Generation of Coherent Radiation by a Relativistic Electron Beam in an Ondulator. Part. Accel. Print 1980, 10, 207-216.

15. Kim, K.J. Three-Dimensional Analysis of Coherent Amplification and Self-Amplified Spontaneous Emission in Free-Electron Lasers. Phys. Rev. Lett. 1986, 57, 1871-1874. doi:10.1103/PhysRevLett.57.1871. [CrossRef] [PubMed] 
16. Lee, T.Y.; Kang, H.S.; Choi, J. Coherence and saturation of self-amplified spontaneous emission free electron laser. Jpn. J. Appl. Phys. Part 1 Regul. Pap. Short Notes Rev. Pap. 2007, 46, 3120-3122. doi:10.1143/JJAP.46.3120. [CrossRef]

17. Chapman, H.N.; Fromme, P.; Barty, A.; White, T.A.; Kirian, R.A.; Aquila, A.; Hunter, M.S.; Schulz, J.; Deponte, D.P.; Weierstall, U.; et al. Femtosecond X-ray protein nanocrystallography. Nature 2011, 470, 73-78. doi:10.1038/nature09750. [CrossRef] [PubMed]

18. Kirian, R.A.; Wang, X.; Weierstall, U.; Schmidt, K.E.; Spence, J.C.H.; Hunter, M.; Fromme, P.; White, T.; Chapman, H.N.; Holton, J. Femtosecond protein nanocrystallography-Data analysis methods. Opt. Express 2010, 18, 5713-5723. doi:10.1364/OE.18.005713. [CrossRef]

19. White, T.A.; Kirian, R.A.; Martin, A.V.; Aquila, A.; Nass, K.; Barty, A.; Chapman, H.N. CrystFEL: A software suite for snapshot serial crystallography. J. Appl. Cryst. 2012, 45, 335-341. doi:10.1107/S0021889812002312. [CrossRef]

20. Rossmann, M.G.; Leslie, A.G.W.; Abdel-Meguid, S.S.; Tsukihara, T.; IUCr. Processing and post-refinement of oscillation camera data. J. Appl. Crystallogr. 1979, 12, 570-581. doi:10.1107/S0021889879013273. [CrossRef]

21. Winkler, F.K.; Schutt, C.E.; Harrison, S.C. The oscillation method for crystals with very large unit cells. Acta Crystallogr. Sect. A 1979, 35, 901-911. doi:10.1107/S0567739479002035. [CrossRef]

22. White, T.A. Post-refinement method for snapshot serial crystallography. Philos. Trans. R. Soc. B Biol. Sci. 2014, 369, 20130330. doi:10.1098/rstb.2013.0330. [CrossRef]

23. Kabsch, W. Processing of X-ray snapshots from crystals in random orientations. Acta Crystallogr. Sect. D Biol. Crystallogr. 2014, 70, 2204-2216. doi:10.1107/S1399004714013534. [CrossRef] [PubMed]

24. Ginn, H.M.; Brewster, A.S.; Hattne, J.; Evans, G.; Wagner, A.; Grimes, J.M.; Sauter, N.K.; Sutton, G.; Stuart, D.I. A revised partiality model and post-refinement algorithm for X-ray free-electron laser data. Acta Crystallogr. Sect. D Biol. Crystallogr. 2015, 71, 1400-1410. doi:10.1107/S1399004715006902. [CrossRef] [PubMed]

25. White, T.A.; Mariani, V.; Brehm, W.; Yefanov, O.; Barty, A.; Beyerlein, K.R.; Chervinskii, F.; Galli, L.; Gati, C.; Nakane, T.; et al. Recent developments in CrystFEL. J. Appl. Crystallogr. 2016, 49, 680-689. doi:10.1107/S1600576716004751. [CrossRef]

26. Ginn, H.M.; Evans, G.; Sauter, N.K.; Stuart, D.I. On the release of cppxfel for processing X-ray free-electron laser images. J. Appl. Crystallogr. 2016, 49, 1065-1072. doi:10.1107/S1600576716006981. [CrossRef] [PubMed]

27. Sauter, N.K. XFEL diffraction: Developing processing methods to optimize data quality. J. Synchrotron Radiat. 2015, 22, 239-248. doi:10.1107/S1600577514028203. [CrossRef] [PubMed]

28. Meents, A.; Wiedorn, M.O.; Srajer, V.; Henning, R.; Sarrou, I.; Bergtholdt, J.; Barthelmess, M.; Reinke, P.Y.A.; Dierksmeyer, D.; Tolstikova, A.; et al. Pink-beam serial crystallography. Nat Commun 2017, 8, 1281. doi:10.1038/s41467-017-01417-3. [CrossRef]

29. Tolstikova, A.; Levantino, M.; Yefanov, O.; Hennicke, V.; Fischer, P.; Meyer, J.; Mozzanica, A.; Redford, S.; Crosas, E.; Opara, N.L.; et al. $1 \mathrm{kHz}$ fixed-target serial crystallography using a multilayer monochromator and an integrating pixel detector. IUCrJ 2019, 6, 927-937. doi:10.1107/S205225251900914X. [CrossRef]

30. Hernandez, A.S.; Prat, E.; Bettoni, S.; Beutner, B.; Reiche, S. Generation of large-bandwidth X-ray free-electron-laser pulses. Phys. Rev. Accel. Beams 2016, 19, 1-9. doi:10.1103/PhysRevAccelBeams.19.090702. [CrossRef]

31. Prat, E.; Dijkstal, P.; Ferrari, E.; Reiche, S. Demonstration of Large Bandwidth Hard X-Ray Free-Electron Laser Pulses at SwissFEL. Phys. Rev. Lett. 2020, 124, 074801. doi:10.1103/PhysRevLett.124.074801. [CrossRef]

32. Guetg, M.W.; Bane, K.L.F.; Brachmann, A.; Fisher, A.S.; Harrison, M.A.; Huang, Z.; Krejcik, P.; Lutman, A.A.; Maxwell, T.J.; Novokhatski, A.; et al. Commissioning of the RADIABEAM/SLAC dechirper. In Proceedings of IPAC2016, Busan, Korea, 8-13 May 2016; pp. 1-4.

33. Lutman, A.A.; Bane, K.; Ding, Y.; Emma, C.; Guetg, M.W.; Guo, Z.; Hemsing, E.; Huang, Z.; Krzywinski, J.; Macarthur, J.P.; et al. XFEL Operational Flexibility due to the Dechirper System. In Proceedings of the 10th International Partile Accelerator Conference (IPAC2019), Melbourne, Australia, 19-24 May 2019; pp. 2219-2223; doi:10.18429/jacow-ipac2019-wexplm1. [CrossRef]

34. Moffat, K. The frontiers of time-resolved macromolecular crystallography: Movies and chirped X-ray pulses. Faraday Discuss. 2002, 122, 65-77. doi:10.1039/b201620f. [CrossRef]

35. Reiche, S. GENESIS 1.3: A fully 3D time-dependent FEL simulation code. Nucl. Instrum. Methods Phys. Res. Sect. A Accel. Spectrometers Detect. Assoc. Equip. 1999, 429, 243-248. doi:10.1016/S0168-9002(99)00114-X. [CrossRef] 
36. Saldin, E.L.; Schneidmiller, E.A.; Yurkov, M.V. FAST: A three-dimensional time-dependent FEL simulation code. Nucl. Instrum. Methods Phys. Res. Sect. A Accel. Spectrometers Detect. Assoc. Equip. 1999, 429, $233-237$. doi:10.1016/S0168-9002(99)00110-2. [CrossRef]

37. Campbell, L.T.; McNeil, B.W. Puffin: A three dimensional, unaveraged free electron laser simulation code. Phys. Plasmas 2012, 19. doi:10.1063/1.4752743. [CrossRef]

38. Tanaka, T. SIMPLEX: Simulator and postprocessor for free-electron laser experiments. J. Synchrotron Radiat. 2015, 22, 1319-1326. doi:10.1107/S1600577515012850. [CrossRef] [PubMed]

39. Tran, T.; Wurtele, J. TDA-A three-dimensional axisymmetric code for free-electron-laser (FEL) simulation. Comput. Phys. Commun. 1989, 54, 263-272. doi:10.1016/0010-4655(89)90090-8. [CrossRef]

40. Reiche, S. Update on the FEL code Genesis 1.3. In Proceedings of the 36th International Free-Electron Laser Conference, Basel, Switzerland, 25-28 August 2014; p. 403.

41. Dejoie, C.; Mccusker, L.B.; Baerlocher, C.; Abela, R.; Patterson, B.D.; Kunz, M.; Tamura, N. Using a non-monochromatic microbeam for serial snapshot crystallography. J. Appl. Cryst. 2013, 46, 791-794. doi:10.1107/S0021889813005888. [CrossRef]

42. Lovell, B.C.; Boashash, B.; Williamson, R.C. The Relationship Between Instantaneous Frequency and Time-Frequency Representations. IEEE Trans. Signal Process. 1993, 41, 1458-1461. doi:10.1109/78.205756. [CrossRef]

43. Stankovic, L. A Method for Time-Frequency Analysis. IEEE Trans. Signal Process. 1994, 42, $225-229$. [CrossRef]

44. Ville, J. Theorie et Application de la Notion de Signal Analytic; Cables et Transmissions: Paris, France, 1948; pp. 61-74.

45. Wigner, E. On the quantum correction for thermodynamic equilibrium. Phys. Rev. 1932, 40, 749-759. doi:10.1103/PhysRev.40.749. [CrossRef]

46. Cohen, L. Instantaneous bandwidth. Proc. SPIE 1992, 9476, 1168-1171. doi:10.1117/12.2180133. [CrossRef]

47. Hassan, M.T.; Luu, T.T.; Moulet, A.; Raskazovskaya, O.; Zhokhov, P.; Garg, M.; Karpowicz, N.; Zheltikov, A.M.; Pervak, V.; Krausz, F.; et al. Optical attosecond pulses and tracking the nonlinear response of bound electrons. Nature 2016, 530, 66-70. doi:10.1038/nature16528. [CrossRef] [PubMed]

48. Huang, S.; Ding, Y.; Feng, Y.; Hemsing, E.; Huang, Z.; Krzywinski, J.; Lutman, A.A.; Marinelli, A.; Maxwell, T.J.; Zhu, D. Generating Single-Spike Hard X-Ray Pulses with Nonlinear Bunch Compression in Free-Electron Lasers. Phys. Rev. Lett. 2017, 119, 1-6. doi:10.1103/PhysRevLett.119.154801. [CrossRef] [PubMed]

49. Li, B. X-Ray Photon Temporal Diagnostics for the European XFEL; Technical Report; European X-Ray Free-Electron Laser Facility GmbH: Hamburg, Germany, 2012.

50. Helliwell, J.R. Single-crystal X-ray techniques. In International Tables for Crystallography, 3rd ed.; Prince, E., Ed.; Kluwer Academic Publishers: Dordrecht, The Netherlands; Boston, MA, USA; London, UK, 2004; Chapter 2.2, Volume C, pp. 26-41.

51. Inubushi, Y.; Tono, K.; Togashi, T.; Sato, T.; Hatsui, T.; Kameshima, T.; Togawa, K.; Hara, T.; Tanaka, T.; Tanaka, H.; et al. Determination of the Pulse Duration of an X-Ray Free Electron Laser Using Highly Resolved Single-Shot Spectra. Phys. Rev. Lett. 2012, 109, 144801. doi:10.1103/PhysRevLett.109.144801. [CrossRef] [PubMed]

52. Altarelli, M.; Brinkmann, R.; Chergui, M.; Decking, W.; Dobson, B.; Düsterer, S.; Grübel, G.; Graeff, W.; Graafsma, H.; Hajdu, J.; et al. The European X-Ray Free-Electron Laser Technical Design Report X FEL X-Ray Free-Ele Ctron Laser; Technical Report; Deutsches Elektronen-Synchrotron: Hamburg, Germany, 2007.

53. Follath, R.; Flechsig, U.; Milne, C.; Szlachetko, J.; Ingold, G.; Patterson, B.; Patthey, L.; Abela, R. Optical design of the ARAMIS-beamlines at SwissFEL. AIP Conf. Proc. 2016, 1741, 020009. doi:10.1063/1.4952788. [CrossRef]

54. Liang, M.; Williams, G.J.; Messerschmidt, M.; Seibert, M.M.; Montanez, P.A.; Hayes, M.; Milathianaki, D.; Aquila, A.; Hunter, M.S.; Koglin, J.E.; et al. The Coherent X-ray Imaging instrument at the Linac Coherent Light Source. J. Synchrotron Radiat. 2015, 22, 514-519. doi:10.1107/S160057751500449X. [CrossRef]

55. Sierra, R.G.; Batyuk, A.; Sun, Z.; Aquila, A.; Hunter, M.S.; Lane, T.J.; Liang, M.; Yoon, C.H.; Alonso-Mori, R.; Armenta, R.; et al. The Macromolecular Femtosecond Crystallography Instrument at the Linac Coherent Light Source. J. Synchrotron Radiat. 2019, 26, 346-357. doi:10.1107/S1600577519001577. [CrossRef] 
56. van Thor, J.J.; Warren, M.M.; Lincoln, C.N.; Chollet, M.; Lemke, H.T.; Fritz, D.M.; Schmidt, M.; Tenboer, J.; Ren, Z.; Srajer, V.; et al. Signal to noise considerations for single crystal femtosecond time resolved crystallography of the Photoactive Yellow Protein. Faraday Discuss. 2014, 171, 439-455. doi:10.1039/C4FD00011K. [CrossRef]

57. Diederichs, K. Simulation of X-ray frames from macromolecular crystals using a ray-tracing approach. Acta Crystallogr. Sect. D Biol. Crystallogr. 2009, 65, 535-542. doi:10.1107/S0907444909010282. [CrossRef]

58. van Thor, J.J.; Madsen, A. A split-beam probe-pump-probe scheme for femtosecond time resolved protein X-ray crystallography. Struct. Dyn. 2015, 2, 014102. doi:10.1063/1.4906354. [CrossRef]

59. Helliwell, J.R.; Habash, J.; Cruickshank, D.W.J.; Harding, M.M.; Greenhough, T.J.; Campbell, J.W.; Clifton, I.J.; Elder, M.; Machin, P.A.; Papiz, M.Z.; et al. The recording and analysis of synchrotron X-radiation Laue diffraction photographs. J. Appl. Crystallogr. 1989, 22, 483-497. doi:10.1107/S0021889889006564. [CrossRef]

60. Szebenyi, D.M.E.; Bilderback, D.H.; LeGrand, A.; Moffat, K.; Schildkamp, W.; Smith Temple, B.; Teng, T. Quantitive analysis of Laue diffraction patterns recorded with a 120 ps exposure from an X-ray undulator. J. Appl. Crystallogr. 1992, 25, 414-423. doi:10.1107/S0021889891014826. [CrossRef]

61. Ren, Z.; Moffat, K. Deconvolution of Energy Overlaps in Laue Diffraction. J. Appl. Crystallogr. 1995, 28 , $482-494$. doi:10.1107/S0021889895003219. [CrossRef]

62. Arzt, S.; Campbell, J.W.; Harding, M.M.; Hao, Q.; Helliwell, J.R. LSCALE-The new normalization, scaling and absorption correction program in the Daresbury Laue software suite. J. Appl. Crystallogr. 1999, 32, 554-562. doi:10.1107/S0021889898015350. [CrossRef]

63. Šrajer, V.; Crosson, S.; Schmidt, M.; Key, J.; Schotte, F.; Anderson, S.; Perman, B.; Ren, Z.; Teng, T.; Bourgeois, D.; et al. Extraction of accurate structure-factor amplitudes from Laue data: Wavelength normalization with wiggler and undulator X-ray sources. J. Synchrotron Radiat. 2000, 7, $236-244$. doi:10.1107/S0909049500004672. [CrossRef] [PubMed]

64. Sanchez-Gonzalez, A.; Johnson, A.S.; Fitzpatrick, A.; Hutchison, C.D.M.; Fare, C.; Cordon-Preciado, V.; Dorlhiac, G.; Ferreira, J.L.; Morgan, R.M.; Marangos, J.P.; et al. Coincidence timing of femtosecond optical pulses in an X-ray free electron laser. J. Appl. Phys. 2017, 122, 203105. doi:10.1063/1.5012749. [CrossRef]

65. Harmand, M.; Coffee, R.; Bionta, M.R.; Chollet, M.; French, D.; Zhu, D.; Fritz, D.M.; Lemke, H.T.; Medvedev, N.; Ziaja, B.; et al. Achieving few-femtosecond time-sorting at hard X-ray free-electron lasers. Nat. Photonics 2013, 7, 215-218. doi:10.1038/nphoton.2013.11. [CrossRef]

66. Lemke, H.T.; Weaver, M.; Chollet, M.; Robinson, J.; Glownia, J.M.; Zhu, D.; Bionta, M.R.; Cammarata, M.; Harmand, M.; Coffee, R.N.; et al. Femtosecond optical/hard X-ray timing diagnostics at an FEL: Implementation and performance. Adv. X-ray Free-Electron Lasers II Instrum. 2013, 8778, 87780S. doi:10.1117/12.2017603. [CrossRef]

67. Nisoli, M.; De Silvestri, S.; Svelto, O. Generation of high energy $10 \mathrm{fs}$ pulses by a new pulse compression technique. Appl. Phys. Lett. 1996, 68, 2793-2795. doi:10.1063/1.116609. [CrossRef]

68. Böhle, F.; Kretschmar, M.; Jullien, A.; Kovacs, M.; Miranda, M.; Romero, R.; Crespo, H.; Morgner, U.; Simon, P.; Lopez-Martens, R.; et al. Compression of CEP-stable multi-mJ laser pulses down to $4 \mathrm{fs}$ in long hollow fibers. Laser Phys. Lett. 2014, 11, 6-11. doi:10.1088/1612-2011/11/9/095401. [CrossRef]

69. Jacqmin, H.; Jullien, A.; Mercier, B.; Hanna, M.; Druon, F.; Papadopoulos, D.; Lopez-Martens, R. Passive coherent combining of CEP-stable few-cycle pulses from a temporally divided hollow fiber compressor. Opt. Lett. 2015, 40, 709-712. doi:10.1364/OL.40.000709. [CrossRef]

70. Hwang, S.I.; Park, S.B.; Mun, J.; Cho, W.; Nam, C.H.; Kim, K.T. Generation of a single-cycle pulse using a two-stage compressor and its temporal characterization using a tunnelling ionization method. Sci. Rep. 2019, 9, 1613. doi:10.1038/s41598-018-38220-z. [CrossRef] [PubMed]

71. Eilzer, S.; Wedel, B. Hollow core optical fibers for industrial ultra short pulse laser beam delivery applications. Fibers 2018, 6, 80. doi:10.3390/fib6040080. [CrossRef]

72. Ciappina, M.F.; Perez-Hernandez, J.A.; Landsman, A.S.; Okell, W.A.; Zherebtsov, S.; Forg, B.; Schotz, J.; Seiffert, L.; Fennel, T.; Shaaran, T.; et al. Attosecond physics at the nanoscale. Rep. Prog. Phys. 2017, 80, 054401. [CrossRef] [PubMed]

73. Gonçalves, C.S.; Silva, A.S.; Navas, D.; Miranda, M.; Silva, F.; Crespo, H.; Schmool, D.S. A Dual-Colour Architecture for Pump-Probe Spectroscopy of Ultrafast Magnetization Dynamics in the Sub-10-femtosecond Range. Sci. Rep. 2016, 6, 22872. doi:10.1038/srep22872. [CrossRef] [PubMed] 
74. Chang, H.T.; Zürch, M.; Kraus, P.M.; Borja, L.J.; Neumark, D.M.; Leone, S.R. Simultaneous generation of sub-5-femtosecond $400 \mathrm{~nm}$ and $800 \mathrm{~nm}$ pulses for attosecond extreme ultraviolet pump-probe spectroscopy. Opt. Lett. 2016, 41, 5365. doi:10.1364/OL.41.005365. [CrossRef]

75. Kohmoto, T.; Fukui, Y.; Furue, S.; Nakayama, K.; Fukuda, Y. Propagation of femtosecond light pulses in a dye solution: Nonadherence to the conventional group velocity. Phys. Rev. E Stat. Nonlinear Soft Matter Phys. 2006, 74, 1-5. doi:10.1103/PhysRevE.74.056603. [CrossRef]

76. Hutchison, C.D.; van Thor, J.J. Populations and coherence in femtosecond time resolved X-ray crystallography of the photoactive yellow protein. Int. Rev. Phys. Chem. 2017, 36, 117-143. doi:10.1080/0144235X.2017.1276726. [CrossRef]

77. Walmsley, I.; Waxer, L.; Dorrer, C. The role of dispersion in ultrafast optics. Rev. Sci. Instrum. 2001, 72, 1-29. doi:10.1063/1.1330575. [CrossRef]

78. VanEngen Spivey, A.G.; Seid, N. Group velocity dispersion of dyes in solution measured with white-light interferometry. Appl. Opt. 2011, 50, 194-202. doi:10.1364/AO.50.000194. [CrossRef]

79. Coello, Y.; Xu, B.; Miller, T.L.; Lozovoy, V.V.; Dantus, M. Group-velocity dispersion measurements of water, seawater, and ocular components using multiphoton intrapulse interference phase scan. Appl. Opt. 2007, 46, 8394-8401. doi:10.1364/AO.46.008394. [CrossRef]

80. Roessler, C.; Agarwal, R.; Allaire, M.; Alonso-Mori, R.; Andi, B.; Bachega, J.; Bommer, M.; Brewster, A.; Browne, M.; Chatterjee, R.; et al. Acoustic Injectors for Drop-On-Demand Serial Femtosecond Crystallography. Structure 2016, 24, 631-640. doi:10.1016/J.STR.2016.02.007. [CrossRef] [PubMed]

81. Cole, T.; Kathman, A.; Koszelak, S.; Mcpherson, A. Determination of Local Refractive Index for Protein and Virus Crystals in Solution by Mach-Zehnder Interferometry. Anal. Biochem. 1995, 231, 92-98. doi:10.1006/abio.1995.1507. [CrossRef] [PubMed]

82. Fredericks, W.; Hammonds, M.; Howard, S.; Rosenberger, F. Density, thermal expansivity, viscosity and refractive index of lysozyme solutions at crystal growth concentrations. J. Cryst. Growth 1994, 141, 183-192. doi:10.1016/0022-0248(94)90111-2. [CrossRef]

83. Polynkin, P.; Kolesik, M. Critical power for self-focusing in the case of ultrashort laser pulses. Phys. Rev. A 2013, 87, 53829. doi:10.1103/PhysRevA.87.053829. [CrossRef]

84. Christov, I.P.; Kapteyn, H.C.; Murnane, M.M.; Huang, C.P.; Zhou, J. Space-time focusing of femtosecond pulses in a Ti:sapphire laser. Opt. Lett. 1995, 20, 309. doi:10.1364/OL.20.000309. [CrossRef] [PubMed]

85. Zozulya, A.A.; Diddams, S.A. Dynamics of self-focused femtosecond laser pulses in the near and far fields. Opt. Express 1999, 4, 336. doi:10.1364/oe.4.000336. [CrossRef]

86. Crego, A.; Conejero Jarque, E.; San Roman, J. Influence of the spatial confinement on the self-focusing of ultrashort pulses in hollow-core fibers. Sci. Rep. 2019, 9, 1-12. doi:10.1038/s41598-019-45940-3. [CrossRef]

87. Kandidov, V.; Dormidonov, A.; Kosareva, O.; Chin, S.; Liu, W. Self-focusing and Filamentation of Powerful Femtosecond Laser Pulses. Top. Appl. Phys. 2008, 114, 413-438. doi:10.1007/978-0-387-34727-1. [CrossRef]

88. Gevorkov, Y.; Barty, A.; Brehm, W.; White, T.A.; Tolstikova, A.; Wiedorn, M.O.; Meents, A.; Grigat, R.R.; Chapman, H.N.; Yefanov, O. pinkIndexer-A universal indexer for pink-beam X-ray and electron diffraction snapshots. Acta Crystallogr. Sect. A Found. Adv. 2020, 76. doi:10.1107/S2053273319015559. [CrossRef]

(C) 2020 by the authors. Licensee MDPI, Basel, Switzerland. This article is an open access article distributed under the terms and conditions of the Creative Commons Attribution (CC BY) license (http://creativecommons.org/licenses/by/4.0/). 